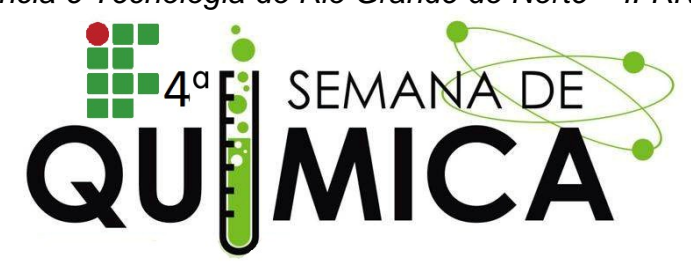

\title{
O USO DO GESSO, SUAS PROPRIEDADES E MODELO DE LIGAÇÃO QUÍMICA
}

SILVA, C. R. A. (IFRN); BATISTA, B. K. C. (IFRN); LEITE, I. M. (IFRN); DOS SANTOS, N. N. N. (IFRN); SANTOS, S. DA C. (IFRN)

Palavras Chave: Gesso, Propriedades, Utilização.

\section{INTRODUÇÃO}

O gesso é um material proveniente da gipsita, encontrada abundantemente em bacias sedimentares, e de acordo com suas propriedades e modelo de ligação química lhe é conferido usos específicos. Devido ao processo de calcinação resultam-se dois tipos de gesso, sendo esses: gesso alfa e gesso beta. Tendo em vista que as propriedades físicas e químicas de uma substância estão diretamente relacionadas com seu modelo de ligação química, o objetivo deste trabalho foi estudar a relação existente entre as propriedades do gesso e seu modelo de ligação química com a sua utilização.

\section{METODOLOGIA}

A metodologia utilizada consiste em revisão bibliográfica na qual se procurou analisar as propriedades do gesso e o modelo de ligação química para entender as suas diversificadas utilizações.

\section{RESULTADOS E DISCUSSÕES}

O gesso é um sulfato de cálcio desidratado cuja fórmula química é $\mathrm{CaSO}_{4}+1 / 2 \mathrm{H}_{2} \mathrm{O}$. Trata-se de um composto iônico com determinadas propriedades. Algumas dessas propriedades podem ser analisadas por meio da tabela 1 Propriedades do gesso e explicações.

Tabela 1 - Propriedades do gesso e explicações

\begin{tabular}{|l|l|}
\hline \multicolumn{1}{|c|}{ Propriedades } & \multicolumn{1}{|c|}{ Explicação } \\
\hline $\begin{array}{l}\text { Condutibilidade } \\
\text { elétrica }\end{array}$ & $\begin{array}{l}\text { Em solução aquosa ou fundida, pois os } \\
\text { íons estão libertos entre si. }\end{array}$ \\
\hline $\begin{array}{l}\text { Equilíbrio } \\
\text { higroscópico: }\end{array}$ & $\begin{array}{l}\text { A absorção e liberação de umidade ao } \\
\text { ambiente confere aos revestimentos }\end{array}$ \\
\hline
\end{tabular}

4를 Semana de Química - IFRN, 2016

https://doi.org/10.4322/2526-4664.008

ISSN 2526-4664

\begin{tabular}{|l|l|}
\hline & $\begin{array}{l}\text { de gesso um elevado poder de } \\
\text { equilíbrio higroscópico fazendo com } \\
\text { que ele atue como inibidor de } \\
\text { propagação de chamas, liberando } \\
\text { moléculas de água quando em contato } \\
\text { com o fogo. }\end{array}$ \\
\hline $\begin{array}{l}\text { Resistência ao } \\
\text { fogo }\end{array}$ & $\begin{array}{l}\mathrm{O} \text { gesso resiste a temperaturas } \\
\text { menores ou equivalentes a } 120^{\circ} \mathrm{C} .\end{array}$ \\
\hline Solubilidade & $\begin{array}{l}\text { Devido à solubilidade de 1,8g/l, a } \\
\text { utilização do gesso fica restrita a } \\
\text { ambientes internos, onde não haja } \\
\text { contato constante com água. }\end{array}$ \\
\hline
\end{tabular}

Segundo o tipo de calcinação a qual a gipsita está sujeita, resultam dois tipos de gesso com distintas utilizações, o Alfa e o Beta, sendo o Alfa calcinado por via úmida e o Beta por via seca. O gesso alfa é um produto de maior pureza apresentando diversas utilidades nas indústrias de vidro, cerâmicas, farmacêutica, de decoração e automobilística, além de moldes odontológicos e ortopédicos e material escolar (giz). A utilização do gesso alfa como molde odontológico pode ser observada a partir da figura 1.

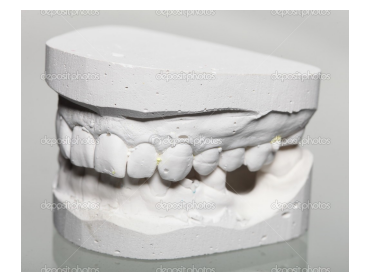

Figura 1 - Gesso alfa como molde odontológico O gesso beta, por sua vez, material heterogêneo, é empregado na construção civil em forma de pré-moldados, paredes divisórias, enchimento de portas corta-fogo e isolante termo acústico. Um exemplo de sua utilização na construção civil pode ser observado por meio da figura 2 . 


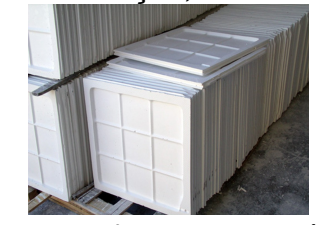

Figura 2 - Gesso beta como pré-moldado

\section{CONCLUSÃO}

O gesso é um material com distintas utilizações, estas dependem basicamente dos seus modelos de ligação química, pureza do material e do processo de produção (sendo o processo de calcinação da gipsita, responsável pela diferenciação entre o gesso alfa e beta, resultando em diferentes usos). É importante reconhecer as diferenças entre os dois tipos de gesso a fim de usá-los de forma correta mediante suas propriedades.

\section{REFERÊNCIAS}

1 Loureiro, Francisco Eduardo de Vries Lapido e Nascimento, Marisa. O gesso nos agrossistemas brasileiros: fontes e aplicações. Disponível em: <http://www.cetem.gov.br/publicacao/CTs/CT 2009-16900.pdf> Acesso em 13 de dezembro de 2014.

2 Bezerra, Marcelo Soares. Relatório técnico 34 Perfil da gipsita Disponível em: <http://www.mme.gov.br/sgm/galeria/arquivo s/plano_duo_decenal/a_mineracao_brasileira_ /P24_RT34_Perfil_da_Gipsita.pdf> Acesso em 08 de janeiro de 2014. ${ }^{3}$ NBR 14619, "Transporte de Produtos Perigosos Incompatibilidade Química", ABNT, 2003.

3 Autor desconhecido. Características do Material. Disponível em: <http://www.arq.ufsc.br/arq5661/trabalhos_2 005-1/gesso/material.html> Acesso em 20 de dezembro de 2013. 